\title{
Effective utilisation of ICT is the key to Business success: Case Study of SMEs in Zimbabwe
}

\author{
Caroline Ruvinga ${ }^{1}$, Munyaradzi Zhou ${ }^{1}$

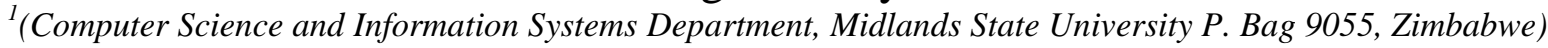

\begin{abstract}
The focus of this paper is to analyse the utilisation of information communication technology (ICT) among small and medium enterprises (SMEs) in Zimbabwe, as one of the major factors contributing to their limited growth. The data was collected using interviews, questionnaires and observations. The findings revealed that most SMEs have and are still increasingly acquiring state of the art information communication technologies but are not fully utilising the technology which has a negative impact on profit margins, market share and overall business effectiveness. The research paper recommends intensive training programs and workshops for SME owners on effective utilisation of ICT for them to experience business growth and success. The findings avail valuable information to both the Zimbabwean SME community and the entire business community in the country in terms of development of economy and creation of employment opportunities.
\end{abstract}

Keywords: acquisition, information communication technology, small and medium enterprises, utilization

\section{INTRODUCTION}

The small and medium enterprises have become an important source of employment and a large contributor to the gross domestic product (GDP) [1] in most developing countries. These SMEs are defined in various ways but in this paper, SMEs are defined as having employees in the range of 1-250 [2]. The advent of the digital era has drastically changed the SME business environment [3] through technological developments which have become a catalyst on business processes [4]. The term information communication technology encompasses a diverse set of technological tools and resources used to communicate, create, disseminate, store and manage information such as computers, internet, mobile phones, hardware and software. However, connectivity technologies have been the greatest achievement in ICT and have unleashed new functionalities for the business community [5]. A strong relationship created between business and information technology [6] requires SME owners to be flexible and adaptive to the ICT so as to sustain their continual survival and growth into large companies.

Business nowadays revolves around information communication technology (ICT) to help organisations gain competitive advantage or meet other strategic enterprise objectives [7]. Information communication technologies are increasingly being adopted in SMEs in different countries such as Malaysia [8], Albania [3], Nigeria [9], New Zealand [10] and world over to achieve more or less the same benefits of increased profit margins, increase in market share, competitive advantage, better image, improved customer relations, reduction in wage bill, reduction in operational costs, flexibility and adaptability of organizational activities, improved employee productivity, increase in return on investment, improvement in product quality and quality of service $[4,5,11,12]$. Indeed ICT has simplified the once complex business operations and has provided an equal platform for SMEs to compete with established companies through the use of internet [8]. Information as the key asset for business success has been availed at a lower cost to the business community for decision making and strategy formulation through networking technologies.

Numerous researches on ICT adoption among SMEs have been conducted in both developed and developing countries such as New Zealand [10], Nigeria [9], Kenya [13], Botswana [12] and Malaysia [14]. The technology has managed to permeate diverse sectors such as manufacturing [13], construction [15] and hospitality with most of the research focusing on internet adoption. The findings from these studies reveal that there is overall improvement on business efficiency and performance [9]. Internet technology brings about flexibility to business activities [16] and contributes immensely to formulation of sound business strategies [17]. Due to the numerous benefits and opportunities brought about by ICT, many SME in developing countries are increasingly adopting ICT and have recorded a positive change in their business operations [3]. Further researches on barriers [11], motivators [12] and uses [18, 19] of ICT have been conducted and various models of adoption have been developed. Indeed almost every business has incorporated some component of ICT in their business and the adoption levels are increasing in Zimbabwe. But the challenge still remains, few SME in developing countries are seen to be graduating into large companies.

To the best of our knowledge, research on the impact of ICT on SMEs in Zimbabwe has not been reported. This paper therefore focuses on investigating the extent to which the utilisation of ICT among small and medium enterprises in Zimbabwe contributes to their growth. 


\subsection{Sampling}

\section{METHODOLOGY}

Case studies of four SME (Case studies A, B, C and D) were investigated. These case studies represent four major industries which are currently driving the Zimbabwean economy (IT, Hospitality, Retail and Construction). The selected SMEs are also leading in terms of ICT adoption. These SMEs are characterised by increased rivalry and numerous new entrances but are experiencing limited growth.

\subsection{Interviews}

A random sample of two SME owners from each of the case studies were interviewed to acquire information concerning their level of ICT acquisition, how they utilise the technologies and the benefits they experienced upon utilisation.

\subsection{Observations}

Random samples of two SMEs in each case study were observed as they performed their day to day business activities with both new and old clients. The researcher also had an opportunity to browse through the websites of at least one website from each case study.

\section{4}

Questionnaires

A set of ten questionnaires was distributed to SME owners in each of the case studies to give an overall of forty administered questionnaires. Out of the forty questionnaires, thirty-three questionnaires were successfully completed. The data from questionnaires was used to gain an insight on SMEs business activities.

\section{RESULTS AND DISCUSSIONS}

\subsection{Demographic data}

Table 1 shows the demographic data of SMEs owners. Most of the respondents were male above the age of 30 years. The age of SME owners ranged from less than 18 years to above 30 years.

Table 1: Demographic data of SMEs owners

\begin{tabular}{|l|c|c|c|c|c|c|}
\hline \multirow{2}{*}{ Case Study } & \multirow{2}{*}{} & \multirow{2}{*}{ Male (\%) } & Female (\%) & \multicolumn{4}{|c|}{ Age (years) } \\
\hline A & 67 & 33 & 11 & 33 & 33 & 22 \\
\hline B & 75 & 25 & 0 & 12 & 38 & 50 \\
\hline C & 67 & 33 & 11 & 33 & 22 & 33 \\
\hline D & 71 & 29 & 0 & 14 & 29 & 57 \\
\hline
\end{tabular}

The academic status of SME owners are shown in Table 2. Most (52\%) SME owners hold a diploma qualification with less than $13 \%$ holding qualifications higher than a diploma. The next highest qualification after the diploma is an O' level (24\%). Six percent of all the cases do not have any academic certification but have a family business background. Less than $1 \%$ holds a doctoral qualification. Basically as the academic qualifications rise beyond diploma level there are fewer SME owners (less than 12\%). Therefore this clearly depicts that most SME owners are not highly educated to the managerial level requirements of at least a degree. Higher educational qualifications from degree level onwards are important in imparting necessary managerial skills to run business. Diploma qualifications are meant to equip employees in lower grades with practical skills. The interviews revealed that most SME owners were comfortable with holding a diploma qualification and did not see the importance of furthering their studies, since they perceived that this does not add value to the business. They said it actually wastes time and money to pursue further studies.

Table 2: Academic status of SMEs owners

\begin{tabular}{|l|c|c|c|c|c|c|c|}
\hline \multirow{2}{*}{ Case Study } & \multicolumn{9}{|c|}{ Academic Qualification (\%) } \\
\cline { 2 - 9 } & None & O' Level & A' Level & Diploma & Degree & Masters & PhD and above \\
\hline A & 0 & 22 & 11 & 55 & 11 & 1 & 0 \\
\hline B & 12 & 38 & 12 & 38 & 0 & 11 & 0 \\
\hline C & 11 & 22 & 0 & 44 & 11 & 0 & 0 \\
\hline D & 0 & 14 & 0 & 71 & 14 & 0 \\
\hline
\end{tabular}

\subsection{Acquisition of ICT}

The ICT acquired for use in SME business operations include networking devices, basic software, websites, digital equipment (desktop, laptop, printer, scanner, copier, land lines, mobile and phone). SMEs invested so much in acquiring most of the ICT for the past 5 years. The percentage acquisition is shown in Fig. 1. 
Case study A had the highest percentage (70\%) of acquired ICT equipment with case study D having the least (57\%). The average percentage acquisition of ICT among SME in Zimbabwe was 64\% which compares favourably with international norms. Most SMEs had communication devices such as landline, mobile phone, printers, computers, internet connection and basic software applications. Devices such as printers and copiers were shared by all the users. Most SME owners revealed that they were still in the process of acquiring more ICT equipment.

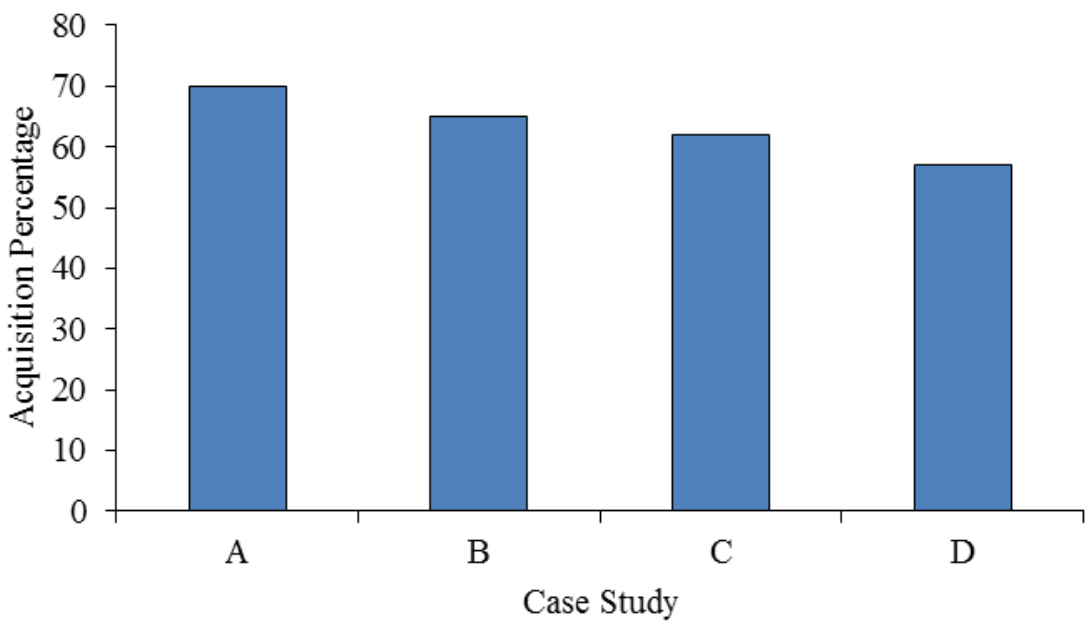

Figure 1: Percentage acquisition of ICT

\subsection{Utilisation of ICT}

The uses of ICT highlighted in the questionnaires include communication (e-mail, chat, forum, video conference, audio/voice communication, text message), advertising, research, e-transacting, e-ordering, device sharing and storage of records. Fig. 2 shows the statistics of utilisation within each sector. Most SME are inadequately using ICT. Case study B recorded the highest utilisation level of $29 \%$ with case study A recording the least level of utilisation (21\%). It was evident from the responses that most SME used computers as a storage device, for typing documents. Mobile phones were also highly used to communicate with clients through text messages. Those with internet connection used it for communication with their clients via email and for device sharing (printer). An average percentage utilisation of ICT among SME in Zimbabwe was found to be $25 \%$. There was no ICT utilization for both business to business (B2B) and business to customer (B2C) transacting. Only one SME used ICT for e-ordering and video conferencing. Interviews revealed that most of these SME viewed ICT as an aiding tool to their business activity but were not aware of how to incorporate some of the ICT applications in their businesses. They viewed ICT as a must have to provide a professional look but not as a must use, since there was limited evidence of using ICT. In some cases organisations with computerised systems recorded their transactions manually for record keeping. Observations also revealed that it took a long time to process an order to completion due to duplication of computerised processes. Numerous forms had to be printed which had to be completed by client then captured into the system. The hard copy was filed and a print out was given back to client to complete the payment. Once payment was completed the receipt number had to be recorded manually then the product or service would be provided to customer. The findings reveal a very low level of utilisation. 


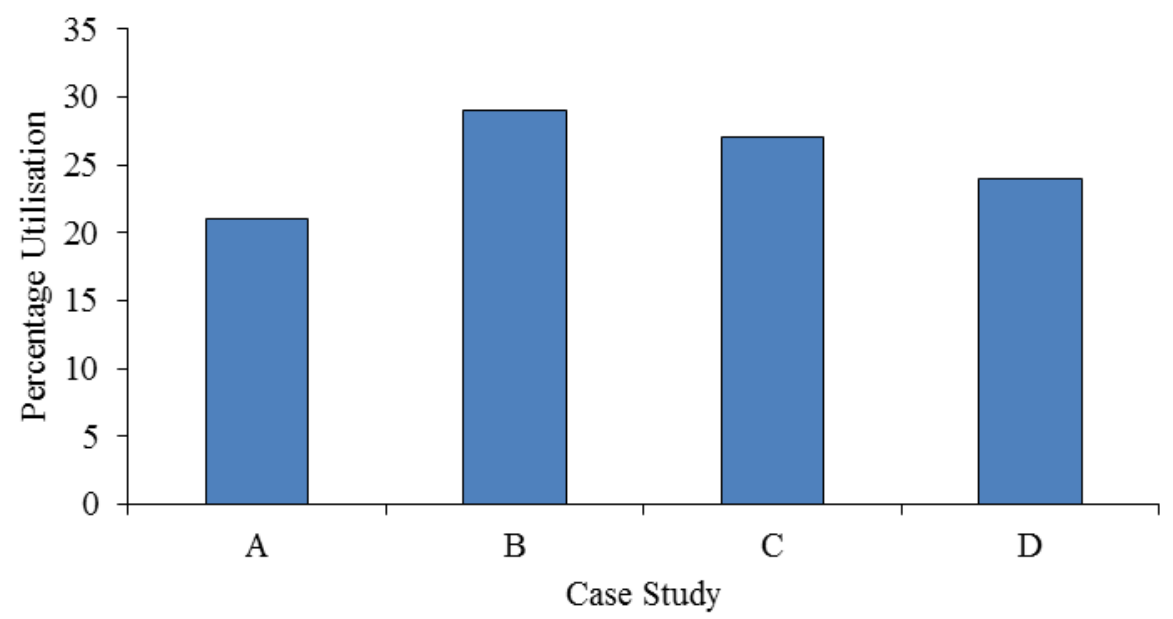

Figure 2: Percentage utilisation in each SME case study

\subsection{Benefits evidenced through ICT utilisation}

The benefits of utilisation include increase in profit, number of local clients, number of international clients, better image, improved product or service quality, cheaper communication, better customer management, new strategies, new opportunities and overall lowering of operational costs. Fig. 3 shows the statistics for benefits of utilisation in the case studies. Case study B recorded the highest percentage $54 \%$ of benefits with case study D recording the least benefits (27\%). The most common benefits that the SMEs acknowledge to have experienced were a better image or recognition, improved customer relations due to improved means of communication (email and text message) and increase in number of local clients. A smaller number of SMEs experienced an increase in the number of international clients and new opportunities through ICT. Interviews revealed that most of the SMEs attributed their success to non ICT related issues such as management style, working alone, recruiting few employees, renting cheaper offices, having fewer ICT components such as phone and internet. The average percentage of benefits realised through utilisation by SME in Zimbabwe was $41 \%$. This value is below $50 \%$ which reflects that the majority of SMEs are not fully experiencing the benefits coupled with ICT adoption.

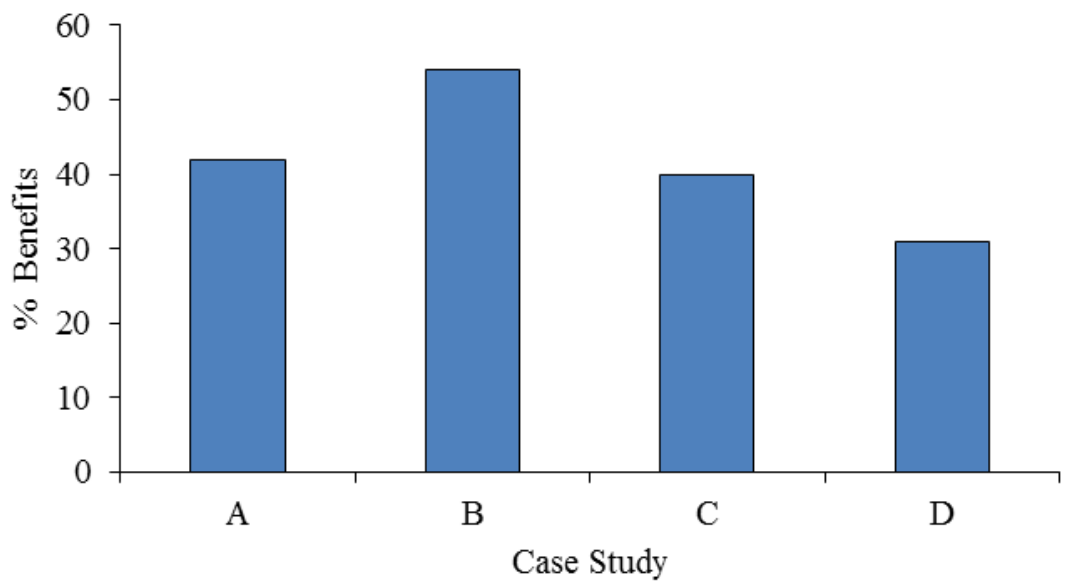

Figure 3: Benefits of utilization in SMEs

\subsection{Analysis of acquisition, utilisation and benefits}

Fig. 4 reflects that the higher the level of utilisation the higher the benefits an SME owner is likely to harness but it does not automatically follow that a higher the level of adoption results in more benefits. Case study A has an adoption of $70 \%$ while case study B has an adoption of $65 \%$ but they differ in the number of benefits. Case study B has higher benefits (54\%) in comparison to A which has $42 \%$. The results clearly depict a pattern which can be interpreted as the higher the utilisation the greater the number of benefits. One can conclude that adopting ICT is not entirely the source of achieving ICT related benefits, the answer lies in full utilisation. 


\section{$\square$ Acquisition $\square$ Use $\square$ Benefits}

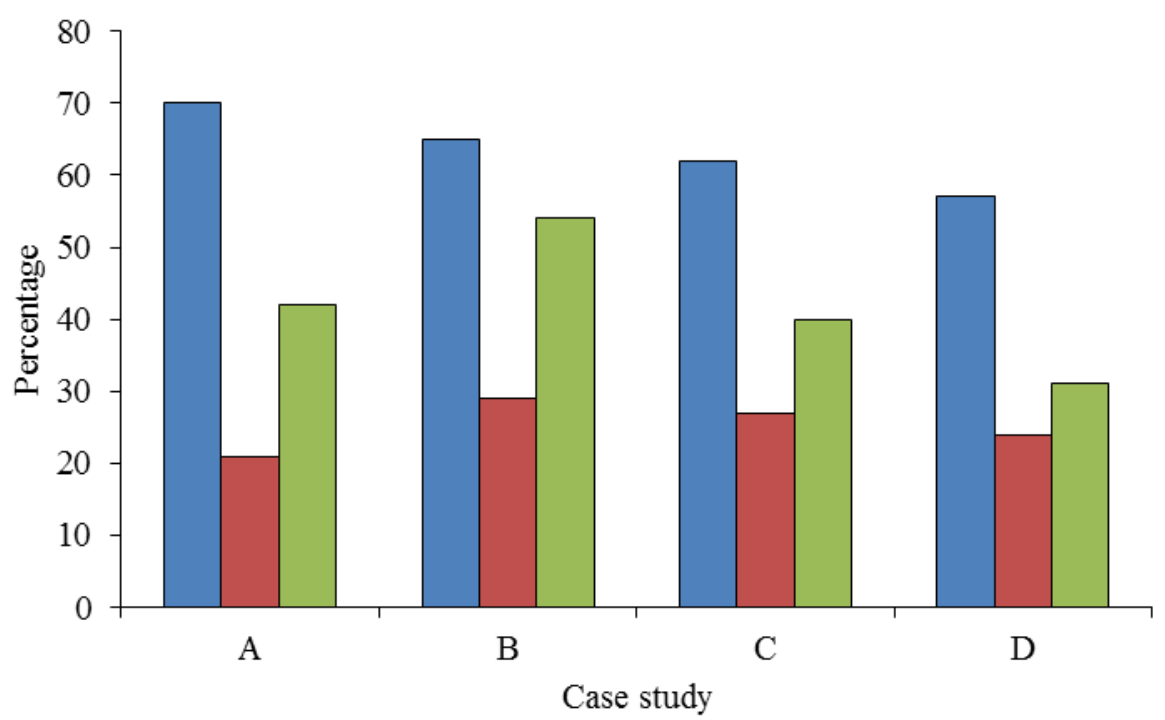

Figure 4: Comparison of acquisition, utilisation and benefits of ICT

\section{CONCLUSION}

The results reveal that most SME in Zimbabwe owned by middle aged males are increasingly acquiring ICT as a means of improving their business activities. The level of ICT utilisation is still very low compared to the level of acquisition with no form of e-transacting being conducted. The most common uses of ICT are for traditional business operations such as storage of records, communication (via email and text message) and device sharing (printer). The findings further indicate a strong relationship between utilisation and benefits as compared to acquisition and benefits. Considering the age and professional qualifications of the majority of SME owners, there is need for the owners to be educated through awareness programs and workshops to encourage the full utilisation of ICT for them to experience business growth and success.

\section{Acknowledgements}

The authors would like to acknowledge Zimbabwe SMEs for providing information which enabled this research to be carried out.

\section{REFERENCES}

[1] L. X. Cunningham, SMEs as motor of growth: A review of China's SMEs development in thirty years (1978-2008), Human Systems Management. 30(1/2), 2011, 39-54.

[2] M. Ayyagari, T. Beck and A.D. Kunt, Small and medium enterprises across the globe: A new database, 3127, 2003. World Bank Publications.

[3] I. Elmazi, H. Vukaj, E, Gega and L. Elmazi, Information technology and its effects in SME. The case of Albania. International Journal of Management Cases, 13, 2011. 291-298.

[4] C. Kowalkowski, D. Kindström and H. Gebauer, ICT as a catalyst for service business orientation. Journal of Business \& Industrial Marketing, 28, 2013, 506-513.

[5] A. Bharadwaj, O.A.E. Sawy, P.A. Pavlou and N. Venkatraman, Digital business strategy: Toward a next generation of insights, MIS Quarterly, 37, 2013, 471-482.

[6] Y.-C. Lee, P.-Y. Chu and H.-L. TSENG, Corporate performance of ICT-enabled business process re-engineering, Industrial Management \& Data Systems, 111, 2011,735-754.

[7] A.K. Garg, R.J.O. Joubert and R. Pellissier, Information systems environmental alignment and business performance: A case study, South African Journal of Business Management, 2005.

[8] K.S. Tan, S.C. Chong, B. Lin, and U.C. Eze, Internet-based ICT adoption: evidence from Malaysian SMEs. Industrial Management \& Data Systems, 109, 2009, 224-244.

[9] I. Apulu and A. Latham, The benefits of ICT adoption: An empirical study of Nigerian SMEs, Proceedings of the International Conference on Information Management \& Evaluation, 2011, 483-491.

[10] S. Locke, ICT Adoption and SME Growth in New Zealand, Journal of American Academy of Business, Cambridge, 4, 2004, 93-102

[11] K.S. Tan, S.C. Chong, B. Lin, and U.C. Eze, Internet-based ICT adoption among SMEs: Demographic versus benefits, barriers, and adoption intention, Journal of Enterprise Information Management, 23, 2010, 27-55.

[12] O, Iyanda and S.O. Ojo, Motivation, influences, and perceived effect of ICT adoption in Botswana organizations, International Journal of Emerging Markets, 3, 2008, 311-322.

[13] S.O. Migiro, Diffusion of ICTs and E-commerce adoption in manufacturing SMEs in Kenya, South African Journal of Libraries \& Information Science, 72, 2006; 35-44

[14] A.S. Shah, Adoption of internet in Malaysian SMEs, Journal of Small Business and Enterprise Development, 16, 2009, $240-255$. 
[15] M. Sarshar and U. Isikdag, A survey of ICT use in the Turkish construction industry, Engineering, Construction and Architectural Management, 11, 2004, 238-247.

[16] K. Celuch, and G. Murphy, SME Internet use and strategic flexibility: The moderating effect of IT market orientation, Journal of Marketing Management, 26, 2010,131-145.

[17] E.T. Bonk, The information revolution and its impact on SME strategy: The Asia pacific economic cooperative forum as a model, Journal of Small Business Management, 34, 1996, 71-77.

[18] M. Ghobakhloo, D. Arias-Aranda, and J. Benitez-Amado, Adoption of e-commerce applications in SMEs, Industrial Management \& Data Systems, 111, 2011,1238-1269.

[19] J. Zhao, ICT4D: Internet adoption and usage among rural users in China, Knowledge, Technology \& Policy 21.1, $2008,9-18$. 